\title{
A Note on Child Policy and Fertility in an Overlapping Generations Small Open Economy: When the Labour Market Institutions Matter
}

\author{
Luciano Fanti ${ }^{1}$ and Luca Gori ${ }^{2}$ \\ ${ }^{1}$ Department of Economics and Management, University of Pisa, Via Cosimo Ridolfi, 10, 56124 Pisa, Italy \\ ${ }^{2}$ Department of Law, University of Genoa, Via Balbi, 30/19, 16126 Genoa, Italy \\ Correspondence should be addressed to Luca Gori, luca.gori@unige.it
}

Received 23 March 2012; Revised 2 July 2012; Accepted 23 July 2012

Academic Editor: Alberto Davila

Copyright (C) 2012 L. Fanti and L. Gori. This is an open access article distributed under the Creative Commons Attribution License, which permits unrestricted use, distribution, and reproduction in any medium, provided the original work is properly cited.

\begin{abstract}
We examine how fertility reacts to the public provision of child allowances in a small open economy with overlapping generations. When the labour market is competitive, we find that a child allowance policy acts as a fertility-enhancing device. In contrast, when the labour market is unionised the child policy may be ineffective.
\end{abstract}

\section{Introduction}

A stylised fact that has emerged in several developed countries is the decline in population growth (see, e.g., [1]). In order to try to reverse the fertility drop, both economists and politicians have suggested the use of family policies to support child rearing of families. Several instruments have been proposed and adopted in European countries as a remedy to low fertility, such as child (cash or in-kind) subsidies, parental leave (paid or unpaid) schemes, parentsfriendly workplaces and the public provision of day-care centres. Moreover, tradable procreation entitlements have also been suggested (see [2]).

A vast theoretical literature has investigated the effects of family policies in both partial equilibrium models (e.g., $[3,4]$ ) and general equilibrium models (e.g., [5-9]) with competitive labour markets. However, scarce attention has been paid to the possible interaction between unions' behaviour (which is a rather ubiquitous feature especially in Europe (see Daveri and Tabellini [10] and Corneo and Marquardt [11])) and the public system of child support, with some exceptions [12].

In this paper we analyse how the public provision of child allowances affects fertility in a small open economy with overlapping generations (OLG) and unions. The paper is related to Fanti and Gori [12], which show that a child tax can effectively be used to get the twofold objective-crucial for developed countries plagued by both high unemployment and low fertility - of reducing unemployment and increasing fertility in a general equilibrium closed economy with an exogenously given minimum wage. This allows us to investigate whether and how child subsidies affect fertility in a model where: (i) the effects of the child allowance on capital accumulation are absent, and (ii) wages are endogenously determined by the union. We find that while under competitive labour markets the child allowance acts as a fertility-enhancing device, under unionised labour markets the child allowance reduces fertility because of the corresponding increase in unemployment. Therefore, in a different context than Fanti and Gori [12], we find that child subsidies may be questioned as an instrument to increase fertility.

The paper is organised as follows. Section 2 outlines the model. Section 3 shows the importance of labour market institutions in determining how child allowances affect fertility in a small open economy. Conclusions are drawn in Section 4.

\section{The Model}

Consider an OLG small open economy with perfect capital mobility that faces an exogenously given interest rate, $r$, 
determined in the world capital market. The economy is populated by rational individuals. Life is divided into childhood and adulthood, the latter period being in turn divided between youth (work time) and old age (retirement time). Children do not make economic decisions, and thus consume a fixed fraction of parents' consumption. Preferences of every young adult individual of generation $t\left(N_{t}\right)$ are described by a homothetic and separable utility function $\left(U_{t}\right)$ defined over consumption when young $\left(c_{1, t}\right)$, consumption when old $\left(c_{2, t+1}\right)$ and the number of children $\left(n_{t}\right)$, as in Eckstein and Wolpin [13], Eckstein et al. [14], and Galor and Weil [15], which are assumed to be a normal good. (This is the so-called weak form of altruism towards children (see [16]), because parents derive utility directly from the number of children they have but do not enjoy the utility derived from their descendants). Individuals work only when they are young and are endowed with one unit of labour inelastically supplied to firms, while receiving the wage $w_{t}$ per unit of labour. A wage is assumed to be fixed by a monopolistic union above the market-clearing level. (See, e.g., Booth [17] and Layard et al. [18]). Therefore, in every period, the labour market does not clear and involuntary unemployment occurs. The aggregate unemployment rate is defined as $u_{t}=\left(N_{t}-L_{t}\right) / N_{t}$, where $L_{t}$ is the labour demand. In this paper, we assume a representative individual that can be employed for the fraction $1-u_{t}$ of time and unemployed for the remaining fraction $u_{t}$. This assumption is usual in the literature [19], since-given the assumption of logarithmic preferences-it is indifferent to separately assume a representative-employed individual and a representativeunemployed individual, rather than a unique representative agent employed (resp., unemployed) for the fraction $1-u_{t}$ (resp., $u_{t}$ ). It is important to note, however, that this may not be true with more general (e.g., interdependent) utility functions.

We also assume that (i) every young agent receives an unemployment benefit $\left(b_{t}\right)$ for the time of unemployment, and (ii) the cost of raising a child (measured in units of market goods) is constant and given by the positive amount $m$, see, for example, Van Groezen et al. [5], Van Groezen and Meijdam, [6] and Fanti and Gori [7].

The budget constraint of each young of generation $t$, therefore, reads as follows:

$$
c_{1, t}+s_{t}+(m-\beta) n_{t}=w_{t}\left(1-u_{t}\right)(1-\tau)+b_{t} u_{t}-\theta_{t},
$$

where $0<\tau_{t}<1$ and $\theta_{t}>0$ are the wage tax rate and lump sum tax used to finance the per child allowance $\beta \in(0, m)$ and the unemployment benefit $b_{t}$, respectively, and $s_{t}$ denotes saving. When old, an individual retires and his/her consumption is constrained by the amount of resources saved when young plus the interest accrued from time $t$ to time $t+1$ at the world interest rate $r$, that is:

$$
c_{2, t+1}=R s_{t} \text {, }
$$

where $R:=1+r$ is the interest factor.

The individual representative of generation $t$ chooses fertility and saving to maximise the utility function

$$
U_{t}=(1-\phi) \ln \left(c_{1, t}\right)+\chi \ln \left(c_{2, t+1}\right)+\phi \ln \left(n_{t}\right),
$$

subject to (1a) and (1b), where $0<\chi<1$ and $0<\phi<1$. The constrained maximisation of (2) gives the following demand for children and saving:

$$
\begin{aligned}
n_{t} & =\frac{\phi}{1+\chi} \cdot \frac{w_{t}\left(1-u_{t}\right)(1-\tau)+b_{t} u_{t}-\theta_{t}}{m-\beta}, \\
s_{t} & =\frac{\chi}{1+\chi}\left[w_{t}\left(1-u_{t}\right)(1-\tau)+b_{t} u_{t}-\theta_{t}\right] .
\end{aligned}
$$

At time $t$ the government runs two separate balanced budget policies to finance the child allowance expenditure $\left(\beta n_{t} N_{t}\right)$ and the unemployment benefit expenditure $\left(b_{t} u_{t} N_{t}\right)$, which are respectively constrained by the amount of tax receipts $\tau_{t} w_{t}\left(1-u_{t}\right) N_{t}$ and $\theta_{t} N_{t}$. Therefore, the time $t$ per worker budget identities of both child allowance and unemployment benefit policies are respectively given by

$$
\begin{gathered}
\tau_{t} w_{t}\left(1-u_{t}\right)=\beta n_{t}, \\
\theta_{t}=b_{t} u_{t} .
\end{gathered}
$$

With regard to the hypothesis of separated balanced budgets, we have followed the authoritative literature by Van Groezen et al. [5], Fenge and Meier [20, 21], Žamac [22] and Van Groezen and Meijdam [6], who analyse the case of the financing of public pensions and child allowances. The main reason for doing this is that the pillars of the public intervention have in practice separate budgets: for instance in several developed countries, public pensions systems, health systems, unemployment insurances, public child care and schooling are managed independently from each other. In fact, as noted by Žamac [22, page 623] "The assumption regarding two separate systems is mainly based on the fact that the existing social security programs have a very weak connection with the education system, if any." And the same applies with regard to the unemployment benefit system and the child allowance system.

Now, by using (4a) and (4b) to substitute for $\tau_{t}$ and $\theta_{t}$ into (3a) and (3b), fertility and saving are given by:

$$
\begin{aligned}
& n_{t}=\frac{\phi w_{t}\left(1-u_{t}\right)}{(1+\chi)(m-\beta)+\phi \beta}, \\
& s_{t}=\frac{\chi(m-\beta) w_{t}\left(1-u_{t}\right)}{(1+\chi)(m-\beta)+\phi \beta} .
\end{aligned}
$$

We assume that firms are identical and act competitively on the market. The aggregate production function at time $t$ is assumed to be of the Cobb-Douglas type, that is $Y_{t}=A K_{t}^{\alpha} L_{t}{ }^{1-\alpha}$, where $Y_{t}, K_{t}$, and $L_{t}=\left(1-u_{t}\right) N_{t}$ are output, the capital stock and the labour input, respectively, $A>0$ and $0<\alpha<1$. The intensive form production function therefore is $y_{t}=A k_{t}^{\alpha}\left(1-u_{t}\right)^{1-\alpha}$, where $y_{t}:=Y_{t} / N_{t}$ and $k_{t}:=K_{t} / N_{t}$ are capital and output per worker, respectively. By assuming that capital fully depreciates at the end of 
every period and output is sold at the unit price, profit maximisation implies the following:

$$
\begin{gathered}
w_{t}=(1-\alpha) A\left(\frac{k_{t}}{1-u_{t}}\right)^{\alpha}, \\
R=\alpha A k_{t}^{\alpha-1} .
\end{gathered}
$$

Since capital is perfectly mobile and the interest rate is constant (at the internationally given level $r$ ), from (7) the capital stock is constant and determined by the no-arbitrage condition on the world capital market (i.e., the equality between the domestic interest rate and the international interest rate), so that:

$$
k_{t}=k=\left(\frac{\alpha A}{R}\right)^{1 /(1-\alpha)} .
$$

The wage is chosen by a monopoly union above the market-clearing level. By following Daveri and Tabellini [10], we assume that a fraction $0<q \leq 1$ of young workers belongs to and are represented by a trade union. (Notice that union membership is exogenously given, while the number of employed individuals is endogenous. Moreover, again following Daveri and Tabellini [10], we assume that unemployment benefits are untaxed). The objective of the union is to set the wage in order to maximise the expected income $\left(I_{t}\right)$ of a risk-neutral representative member, that is

$$
\max \left\{w_{t}\right\} \quad I_{t}=\frac{1-u_{t}}{q} w_{t}\left(1-\tau_{t}\right)+\left(1-\frac{1-u_{t}}{q}\right) b_{t},
$$

subject to

$$
\begin{gathered}
u_{t}=1-\left[\frac{(1-\alpha) A}{w_{t}}\right]^{1 / \alpha} \cdot k, \\
b_{t}=\gamma \bar{w}_{t},
\end{gathered}
$$

where the unemployment rate (10a) is obtained from (6), $0<\gamma<1$ is the replacement rate, $\bar{w}_{t}$ is the competitive or reference wage of the union and $\left(1-u_{t}\right) / q$ represents the fraction of union members that finds a job. (Note that the competitive wage is constant and given by $\bar{w}=(1-\alpha) A k^{\alpha}$ $($ see $(6)))$. Therefore, the optimal wage for the union is

$$
w_{t}=\frac{\gamma \bar{w}_{t}}{(1-\alpha)\left(1-\tau_{t}\right)} .
$$

Combining now (10a) and (11), the unemployment rate becomes the following:

$$
u_{t}=1-\left[\frac{(1-\alpha)\left(1-\tau_{t}\right)}{\gamma}\right]^{1 / \alpha} .
$$

From (11) and (12), we note that $w_{t}>\bar{w}_{t}$ and $0<u_{t}<1$ if and only if $\gamma>(1-\alpha)\left(1-\tau_{t}\right)$ holds.

By using (4a) and (5a), the wage tax rate that balances the child allowance expenditure is constant and equal to

$$
\tau=\frac{\phi \beta}{(1+\chi)(m-\beta)+\phi \beta} .
$$

Therefore, the union's wage and unemployment rate are obtained by exploiting (11), (12), and (13), and they are respectively given by:

$$
\begin{array}{r}
w=\gamma \bar{w} \cdot \frac{(1+\chi)(m-\beta)+\phi \beta}{(1-\alpha)(1+\chi)(m-\beta)}, \\
u=1-\left\{\frac{(1-\alpha)(1+\chi)(m-\beta)}{\gamma[(1+\chi)(m-\beta)+\phi \beta]}\right\}^{1 / \alpha} .
\end{array}
$$

Now, let

$$
n=n[\beta, w(\beta), u(\beta)]
$$

be the fertility rate as a generic function of the child allowance. Then, the total derivative of (15) with respect to $\beta$ gives:

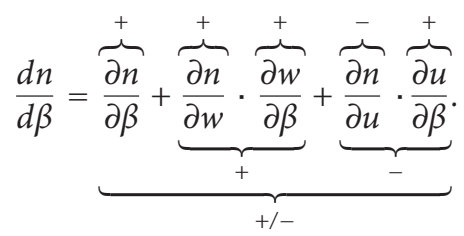

Equation (16) reveals that a rise in the child allowance ambiguously affects fertility. In fact, when $\beta$ varies, there exist (i) a positive direct substitution effect because the cost of children reduces, and (ii) an ambiguous income effect due to the rise in both the union's wage and unemployment rate: the former (resp., latter) effect positively (resp., negatively) affects fertility. (Note that an exogenously given interest rate (that also implies that the wage does not depend on capital accumulation) that characterises a small open economy implies that a general equilibrium effect of the child policy through price changes cannot occur).

Combining (5a), (14a) and (14b), we find that long-run fertility is given by the following equation:

$$
\begin{aligned}
n(\beta)= & \frac{\phi \gamma \bar{w}}{(1-\alpha)(1+\chi)(m-\beta)} \\
& \quad \times\left\{\frac{(1-\alpha)(1+\chi)(m-\beta)}{\gamma[(1+\chi)(m-\beta)+\phi \beta]}\right\}^{1 / \alpha} .
\end{aligned}
$$

\section{Child Subsidy and Fertility}

In this section, we study the effects of child allowances on fertility when the labour market is either unionised (Propositions 1 and 2) or competitive (Corollary 3 ).

From (17) the following propositions hold:

Proposition 1. When the labour market is unionised, the introduction of a child allowance (evaluated at $\beta=0$ ) increases fertility if and only if $\alpha>\hat{\alpha}$. 
Proof. Differentiating (17) with respect to $\beta$ and evaluating it at $\beta=0$ gives:

$$
\left.\frac{\partial n(\beta)}{\partial \beta}\right|_{\beta=0}=\frac{\phi \gamma w((1-\alpha) / \gamma)^{1 / \alpha}[\alpha(1+\chi)-\phi]}{\alpha(1-\alpha)[m(1+\chi)]^{2}} .
$$

Then, $n^{\prime}(0)>0\left(n^{\prime}(0)<0\right)$ if and only if $\alpha>\hat{\alpha}(\alpha<\hat{\alpha})$, where $\hat{\alpha}:=\phi /(1+\chi)$.
Proposition 2. (1) Let $\alpha>\hat{\alpha}$ hold. Then $n(\beta)$ is maximised at $\beta=\beta_{n}$, and $n(\beta)>n(0)$ for any $0<\beta<\hat{\beta}, n(\beta)<n(0)$ for any $0<\hat{\beta}<\beta<m$, where $\beta_{n}:=m[\alpha(1+\chi)-\phi] / \alpha(1+\chi-\phi)$ with $\beta_{n}<\hat{\beta}<m$ is the fertility-maximising child allowance and $\beta=\hat{\beta}$ is a threshold such that $n(\hat{\beta})=n(0)$. (2) Let $\alpha<\hat{\alpha}$ hold. Then, a rise in the child allowance monotonically reduces fertility, and $n(\beta)<n(0)$ for any $0<\beta<m$.

Proof. The proof uses the following derivative:

$$
\frac{\partial n(\beta)}{\partial \beta}=\frac{\phi \gamma \bar{w}\{(1-\alpha)(1+\chi)(m-\beta) / \gamma[(1+\chi)(m-\beta)+\phi \beta]\}^{1 / \alpha}\{m[\alpha(1+\chi)-\phi]-\beta \alpha(1+\chi-\phi)\}}{\alpha(1-\alpha)(1+\chi)(m-\beta)^{2}[(1+\chi)(m-\beta)+\phi \beta]}
$$

If $\alpha>\hat{\alpha}$, then $n^{\prime}(\beta) \frac{\geq}{<} 0$ if and only if $\beta \frac{<}{>} \beta_{n}$. Since $n(0)>0$, $n(\beta)$ is a positive (resp., negative) monotonic function of $\beta$ for any $0<\beta<\beta_{n}$ (resp., $\beta_{n}<\beta<m$ ) and $\lim _{\beta \rightarrow m} n(\beta)=0$, there always exists a threshold value $\beta_{n}<\hat{\beta}<m$ such that $n(\hat{\beta})=n(0)$. Therefore, $n(\beta)>n(0)$ for any $0<\beta<\hat{\beta}$, $n(\beta)<n(0)$ for any $\hat{\beta}<\beta<m$. If $\alpha<\hat{\alpha}, n^{\prime}(\beta)<0$, and $n(\beta)<n(0)$ for any $0<\beta<m$.

Corollary 3. When the labour market is competitive, that is $w=\bar{w}$, a child allowance policy monotonically increases fertility.

Proof. If $w=\bar{w}$, then $u=0$ and $n^{\prime}(\beta)>0$.

Propositions 1 and 2 show that if the output elasticity of capital is small, the introduction of a child allowance monotonically reduces fertility, as the negative income effect due to the increased unemployment rate always prevails. This effect is due to the interaction of the fertility rate with both the union's wage and unemployment rate. When this interaction is absent, that is, the labour market is competitive, the effect of a child allowance on fertility is straightforward, that is labour market institutions matter.

In order to show whether our findings are plausible for actual small open economies, we note that the threshold value of the output elasticity of capital $(\hat{\alpha})$ below which the child allowance reduces fertility depends on both the parents' relative taste for children and the subjective discount factor. Authoritative empirical literature [23] finds that the output elasticity of capital for developed countries is around $1 / 3$, as also point out by Zhang et al. [24]. Then, by assuming that $\chi=0.3[25$, page 25$]$ and $\phi$ is included in the range $(0.44,0.6)$ [24], (Note that we have used a different parametrization with respect to Zhang et al. [24] with regard to preferences. Indeed, Zhang et al. [24, page 501] notice that "The taste for the number of children is in the range $0.8 \leq \eta \leq 1.5$ (which corresponds to $0.44 \leq \phi \leq 0.6$ with respect to our specification of parameters); $\eta>1.5$ seems unlikely since such a high value means that individuals care about the number of children far more than own consumption and the welfare of children. The capital income share parameter is 0.3 (1.4 $\leq \theta \leq 1.3$ is widely used).") we may conclude that even in the less favourable case $(\phi=0.44)$, the child policy acts as a fertility disincentive in developed countries irrespective of the size of the child allowance, especially when individuals care about their children not too less than own consumption.

Our findings require, however, some caveats due to the specific assumptions with regard to preferences, technology, tax financing of both child allowance and unemployment benefit expenditures, childrearing costs, and union's behaviour. In particular, the assumption of the child cost in terms of consumption good instead of time cost deserves some comments. In fact, if child costs were modelled in terms of forgone work time, the labour would become elastically supplied, and thus additional effects of child allowance would emerge: on the one hand, higher participation rates in the labour market ( since child care can be outsourced) and possibly higher taxes may occur; on the other hand, the child subsidy can increase income earned by workers (since more time can be allocated to earning wage in the labour market), so altering the wages negotiated by unions. These additional effects work in the direction of mitigating the negative effect of the child allowance on fertility as suggested in the paper. Moreover, it may be the case that unionised economies with higher participation rates might experience, as conventional wisdom believes, higher fertility rates if child subsidies were provided.

Finally we consider, also for a future comparison with the results of this paper, some results of the vast empirical literature dealing with the effects of various family policy instruments. More in detail, with regard to the type of policies implemented to increase fertility, policy makers have used several instruments: tax incentives (earned income tax credit (EITC) in the US, working tax credit (WTC) in the UK or the french family tax splitting to direct cash transfer to families with children, in turn distinguished in universal child benefits (like those assumed in the present paper) or child care facilities and parental leave schemes. However the empirical estimates of the effects of these instruments on fertility is controversial. (For instance, Haan and Wrohlich 
[26, page 1] note that "The evidence about the success of these policy instruments for fostering female employment or fertility is mixed," while Kalwij [27, page 504] states that "the empirical evidence on the extent to which fertility is affected by family-friendly labour market policies, such as maternity leave and childcare, is scarce and inconclusive").

With regard to the child allowance policy, it has been noted that although the cash transfer scheme is a popular choice in several OECD countries (e.g., Australia, Belgium, France, Germany, New Zealand, South Korea, and Sweden), the "long-run impact of the cash transfer has not been fully tested." [28, page 11]. In particular, with regard to the effects of child subsidies on fertility, it is of interest the casestudy of the universal cash transfer scheme called Allowance for Newborn Children (ANC) implemented in Canada by the provincial government of Quebec from May 1988 to September 1997 to all legal residents of Quebec. In fact, while both Duclos et al. [29], by using data obtained only from vital statistics, and Milligan [30], by using Canadian Household Census data, found a positive effect of the ANC on fertility; Kim [28, page 11] analyses the impact on completed fertility level rather than cross-sectional dataset and shows that "the cash transfer policy have little impact on the lifetime fertility increase." The inconclusiveness of the empirical analysis may be ascribed to several reasons: (i) policies have many dimensions that limit the comparability of a single policy indicator over time or across country [27, page 504]; (ii) the sign of the effect may be significant in the "wrong" direction, because it may reflect the endogeneity of prochild policies in the sense that countries with low fertility may respond by increasing incentives to fertility (e.g., [31, page 16]); (iii) the impact on fertility may seem positive due to the shift on the childbirth, while being ineffective on long-term fertility rates $[28,32]$. However, such controversial empirical findings may also reflect different effects of the same policies due to different economic contexts (e.g., competitive versus unionised labour markets): in this sense this paper offers a theoretical contribution for a possible explanation of the ineffectiveness or even of the "wrong" direction of child subsidy policies, by revealing a mechanism through which a higher tax to finance child care raises unemployment because unions bargain after-tax wages and ultimately leads to a fertility drop. Whether child subsidy policies may be associated with positive or negative fertility effects in countries with high unemployment and low fertility may be a possible task for econometricians and it is beyond of the scope of this paper.

\section{Conclusions}

Three features characterise several European economies: below-replacement fertility, unionised labour markets, and child subsidy policies. This paper has studied whether and how the public provision of child allowances works either as an incentive or disincentive to fertility by using an overlapping generations small open economy with unionised labour. We have shown that while the use of child allowances always acts as a fertility-enhancing device when the labour market is competitive, it can represent a fertility disincentive when the labour market is unionised because of the corresponding rise in unemployment. Moreover, a simple numerical exercise has shown that our findings may be the rule rather than the exception under standard parameter values.

Our findings suggest that the existence of monopolistic unions may be responsible of the possible failure of the public provision of child allowances.

\section{References}

[1] O. Galor, "From stagnation to growth: unified growth theory," in Handbook of Economic Growth, P. Aghion and S. Durlauf, Eds., vol. 1, chapter 4, pp. 171-293, Elsevier, New York, NY, USA, 2005.

[2] D. de La Croix and A. Gosseries, "Population policy through tradable procreation entitlements," International Economic Review, vol. 50, no. 2, pp. 507-542, 2009.

[3] A. Cigno, "Fertility and the tax-benefit system: a reconsideration of the theory of family taxation," Economic Journal, vol. 96, no. 384, pp. 1035-1051, 1986.

[4] P. Apps and R. Rees, "Fertility, taxation and family policy," Scandinavian Journal of Economics, vol. 106, no. 4, pp. 745763, 2004.

[5] B. van Groezen, T. Leers, and L. Meijdam, "Social security and endogenous fertility: pensions and child allowances as siamese twins," Journal of Public Economics, vol. 87, no. 2, pp. 233-251, 2003.

[6] B. van Groezen and L. Meijdam, "Growing old and staying young: population policy in an ageing closed economy," Journal of Population Economics, vol. 21, no. 3, pp. 573-588, 2008.

[7] L. Fanti and L. Gori, "Population and neoclassical economic growth: a new child policy perspective," Economics Letters, vol. 104, no. 1, pp. 27-30, 2009.

[8] M. Momota, "The gender gap, fertility, subsidies and growth," Economics Letters, vol. 69, no. 3, pp. 401-405, 2000.

[9] L. Fanti and L. Gori, "A note on endogenous fertility, child allowances and poverty traps," Economics Letters. In press.

[10] F. Daveri and G. Tabellini, "Unemployment, growth and taxation in industrial countries," Economic Policy, no. 30, pp. 47-104, 2000.

[11] G. Corneo and M. Marquardt, "Public pensions, unemployment insurance, and growth," Journal of Public Economics, vol. 75, no. 2, pp. 293-311, 2000.

[12] L. Fanti and L. Gori, "Child policy solutions for the unemployment problem," Economics Letters, vol. 109, no. 3, pp. 147-149, 2010.

[13] Z. Eckstein and K. I. Wolpin, "Endogenous fertility and optimal population size," Journal of Public Economics, vol. 27, no. 1, pp. 93-106, 1985.

[14] Z. Eckstein, S. Stern, and K. I. Wolpin, "Fertility choice, land, and the Malthusian hypothesis," International Economic Review, vol. 29, no. 2, pp. 353-361, 1988.

[15] O. Galor and D. N. Weil, "The gender gap, fertility, and growth," American Economic Review, vol. 86, no. 3, pp. 374387, 1996.

[16] J. Zhang and J. Zhang, "Social security, intergenerational transfers, and endogenous growth," Canadian Journal of Economics, vol. 31, no. 5, pp. 1225-1241, 1998.

[17] A. L. Booth, The Economics of the Trade Union, Cambridge University Press, Cambridge, UK, 1995. 
[18] R. Layard, S. Nickell, and R. Jackman, Unemployment: Macroeconomic Performance and the Labour Market, Oxford University Press, New York, NY, USA, 2nd edition, 2005.

[19] L. Fanti and L. Gori, "On economic growth and minimum wages," Journal of Economics, vol. 103, no. 1, pp. 59-82, 2011.

[20] R. Fenge and V. Meier, "Pensions and fertility incentives," Canadian Journal of Economics, vol. 38, no. 1, pp. 28-48, 2005.

[21] R. Fenge and V. Meier, "Are family allowances and fertilityrelated pensions perfect substitutes?" International Tax and Public Finance, vol. 16, no. 2, pp. 137-163, 2009.

[22] J. Žamac, "Pension design when fertility fluctuates: the role of education and capital mobility," Journal of Public Economics, vol. 91, no. 3-4, pp. 619-639, 2007.

[23] D. Gollin, "Getting income shares right," Journal of Political Economy, vol. 110, no. 2, pp. 458-474, 2002.

[24] J. Zhang, J. Zhang, and R. Lee, "Mortality decline and long-run economic growth," Journal of Public Economics, vol. 80, no. 3, pp. 485-507, 2001.

[25] D. de la Croix and P. Michel, A Theory of Economic Growth: Dynamics and Policy in Overlapping Generations, Cambridge University Press, Cambridge, UK, 2002.

[26] P. Haan and K. Wrohlich, "Can child care policy encourage employment and fertility? Evidence from a structural model," Labour Economics, vol. 18, no. 4, pp. 498-512, 2011.

[27] A. Kalwij, "The impact of family policy expenditure on fertility in Western Europe," Demography, vol. 47, no. 2, pp. 503-519, 2010.

[28] Y. I. A. Kim, "Lifetime impact of cash transfer on fertility," Working Paper, 2008.

[29] E. Duclos, P. Lefebvre, and P. Merrigan, "A natural experiment on the economics of storks: evidence on the impact of differential family policy on fertility rates in Canada," CREFE Working Paper 136, 2001.

[30] K. Milligan, "Subsidizing the stork: new evidence on tax incentives and fertility," Review of Economics and Statistics, vol. 87, no. 3, pp. 539-555, 2005.

[31] J. Feyrer, B. Sacerdote, and A. D. Stern, "Will the stork return to Europe and Japan? Understanding fertility within developed nations," Journal of Economic Perspectives, vol. 22, no. 3, pp. 3-22, 2008.

[32] Y. I. A. Kim, Impact of birth subsidies on fertility: empirical study of allowance for newborn children, a pronatal policy [Ph.D. thesis], University of Chicago, Chicago, Ill, USA, 2008. 


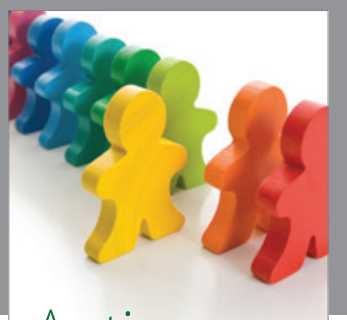

Autism

Research and Treatment
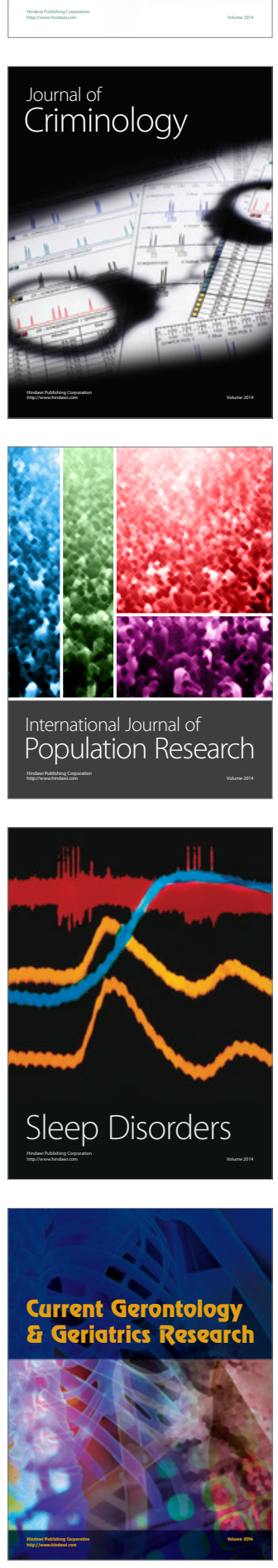
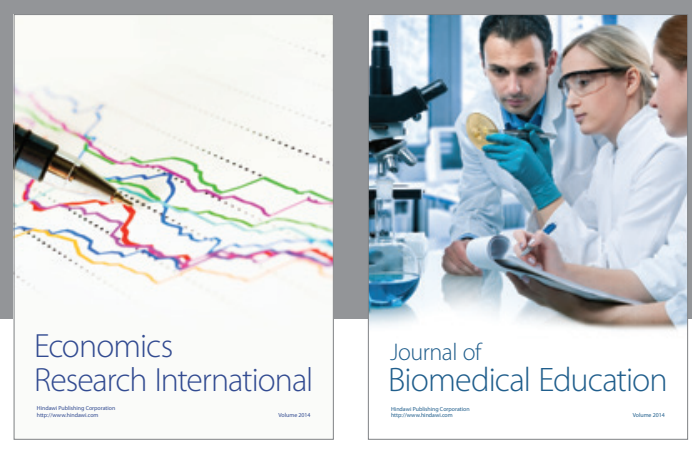

Journal of

Biomedical Education

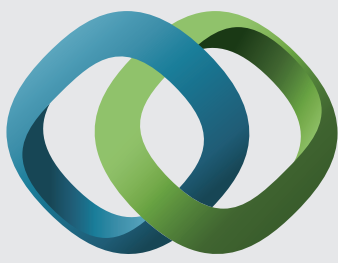

\section{Hindawi}

Submit your manuscripts at

http://www.hindawi.com
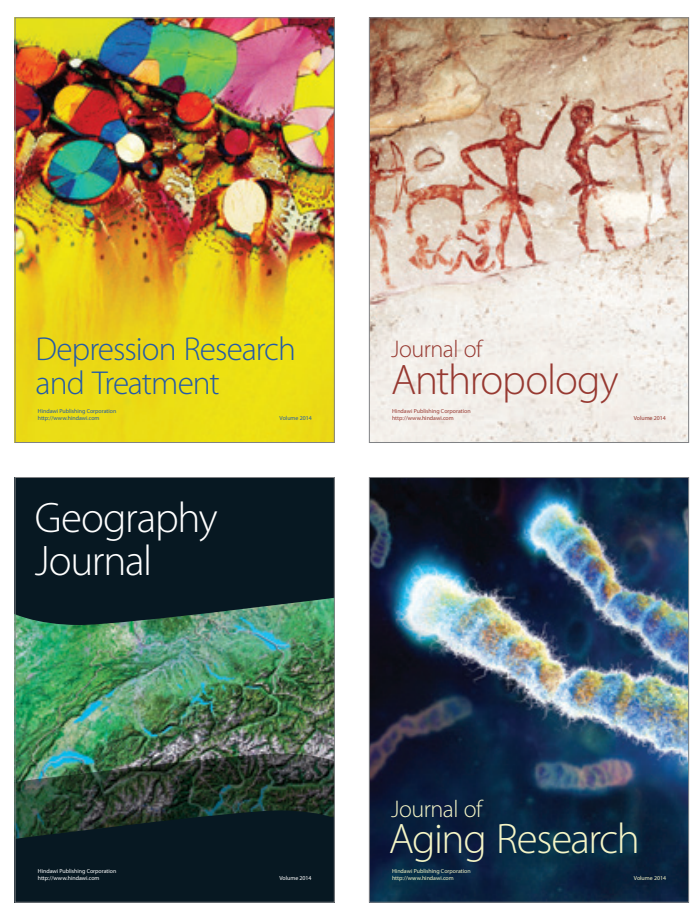

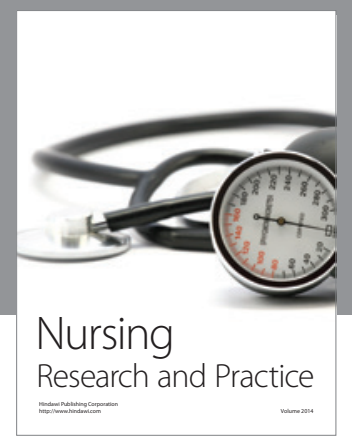

Nursing

Research and Practice

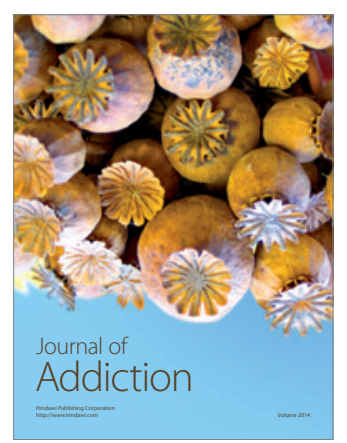

Child Development

Research

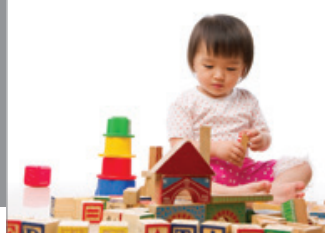

迥
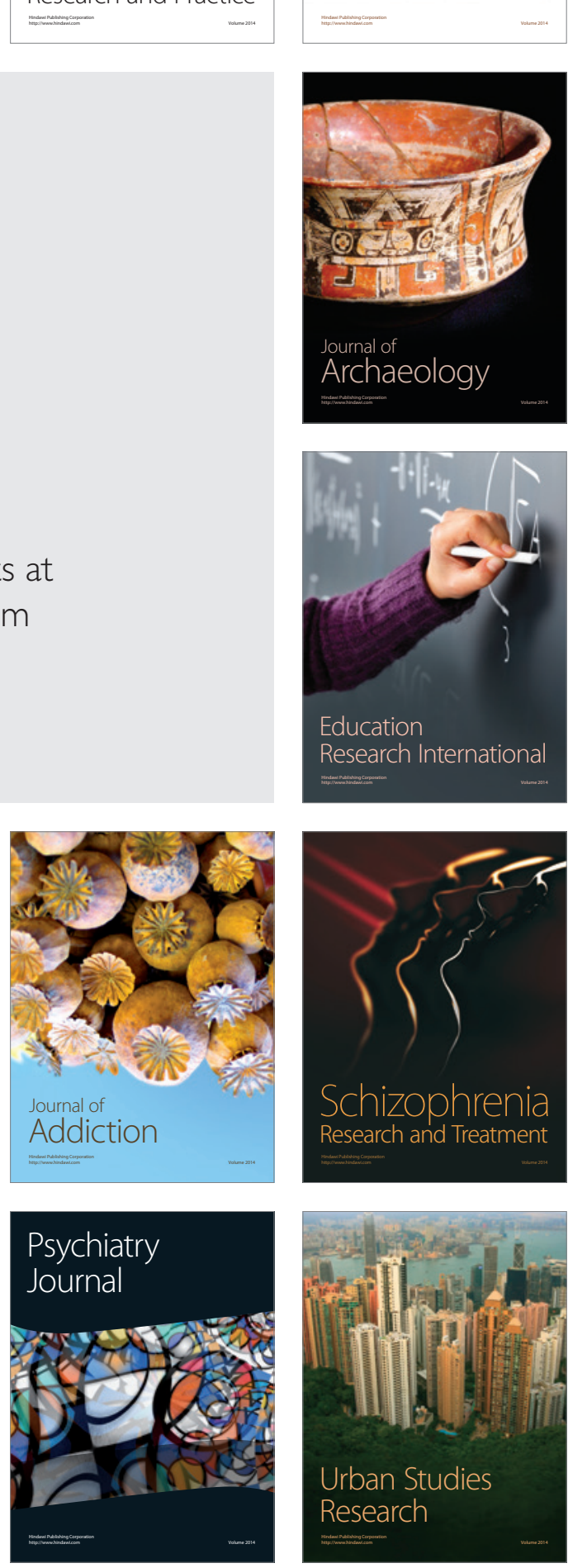